\title{
REDE DE RESPONSABILIDADE SOCIOAMBIENTAL: UMA METODOLOGIA PARA ANÁLISE NO SETOR DE CELULOSE E PAPEL ${ }^{1}$
}

\author{
Regiane Borsato ${ }^{2}$, Samira Kauchakje ${ }^{3}$ e Roberto Rochadelli ${ }^{4}$
}

\begin{abstract}
Resumo - O objetivo deste trabalho foi propor a utilização da análise de redes sociais (ARS) direcionada aos arranjos institucionais, possibilitando a pesquisa empírica da responsabilidade socioambiental no setor florestal. Foi realizado um estudo de caso, no qual se construiu graficamente uma rede a partir da identificação de todas as organizações atuantes em projetos ambientais através de parcerias com empresas do setor. A base de dados empregada foi o Relatório de Responsabilidade Socioambiental da Associação Brasileira de Celulose e Papel (BRACELPA, 2006). Os dados, processados pelo software UCINET, permitiram visualizar interações entre o setor privado, o setor público e o terceiro setor. A partir dessa base de dados foi possível detectar cinco subgrupos de atuação socioambiental formados pelas empresas do setor florestal e suas parceiras, além da existência de diferenças quantitativas e qualitativas entre os arranjos institucionais de cada subgrupo. Esses arranjos podem ser explorados inserindo em futuras análises outros atributos aos atores sociais pertencentes à rede. A metodologia permite a obtenção de dados estratégicos, sendo a Bracelpa possível articuladora e potencializadora da atuação socioambiental das empresas através do fortalecimento dos laços relacionais entre os subgrupos. Este trabalho abordou o conceito de redes sociais e de análise de redes para as Ciências Florestais. Em especial, os resultados apontaram caminhos para novas pesquisas sobre cultura gerencial, multiplicação de informações, dinamização das ações, sinergia com parceiros e potencial de incorporação da metodologia pelas próprias organizações do setor.
\end{abstract}

Palavras-chave: Gestão, Análise de redes, Responsabilidade social e política florestal.

\section{SOCIAL-ENVIRONMENTAL RESPONSIBILITY NETWORK: METHODOLOGY FOR THE ANALYSIS ON THE CELLULOSE AND PAPER SECTOR}

\begin{abstract}
The aim of this paper was to propose the utilization of a network analysis as a methodology to discuss the Social-Environmental Responsibility on forest based companies focused on the articulation among industry, governmental agencies and the outsourced sector. A case study was conducted identifying all the social participants involved in the environmental projects published in the Social-Environmental Responsibility Report of Brazilian Pulp and Paper Association (Bracelpa, 2006). Data was analyzed with UCINET software and allowed visualize interactions among private companies, public sector and the outsourced sector. Five subgroups were detected formed by the companies and their partners. There are quantitative and qualitative differences among subgroup arrangements. These arrangements can be explored inserting new attributes to the actors. The methodology allows for the obtaining strategic information for strengthening actions. Bracelpa can fortify these relations between subgroups. This paper brings the social net concept to forestry science. Specially, the results indicate the possibilities of new research involving culture management, informational multiplication, shares dynamics, partnerships and forestry companies using the methodology.
\end{abstract}

Keywords: Management, Network analysis, Social responsibility and forest policy.

\footnotetext{
${ }^{1}$ Recebido em 30.06.2008 e aceito para publicação em 14.10.2009.

${ }^{2}$ Programa de Pós-Graduação em Meio Ambiente e Desenvolvimento da Universidade Federal do Paraná, UFPR, Brasil. E-mail: <rbregiane@uol.com.br>.

${ }^{3}$ Pontifícia Universidade Católica do Paraná, PUC-PR, Brasil.

${ }^{4}$ Universidade Federal do Paraná, UFPR, Brasil.
} 


\section{INTRODUÇÃO}

Para o setor florestal brasileiro, a temática socioambiental é de especial relevância. Para Oliveira (2003), apesar do consenso no campo da Ciência Florestal quanto aos benefícios sociais e econômicos que o setor tem proporcionado, impactos ambientais e sociais negativos também ocorreram. Gomes (2005) citou que o modelo econômico adotado pelo setor florestal tem sido alvo de críticas de grupos sociais organizados, movimentos sociais ou até mesmo instituições públicas, que percebem nele fonte causadora de exclusão econômica e social e de inúmeros conflitos sociopolíticos.

Segundo Gomes et al. (2006), algumas empresas estão sujeitas a crescentes pressões em termos de exigências ambientais e sociais. Assim, segundo esses autores, um de seus desafios é atingir o equilíbrio entre as diferentes demandas, muitas vezes conflitantes, de todas as partes interessadas e relacionadas com suas atividades industriais e florestais. Nardelli e Griffith (2003a) ressaltaram que o campo organizacional do setor florestal brasileiro é pluralístico, em que os membros seguem diferentes ideologias, valores e modelos. Pode-se pensar que os grandes desafios enfrentados pela atividade florestal estão associados também a essa pluralidade. Oliveira (2007) discutiu amplamente esses desafios, trazendo os problemas e as demandas sociais presentes na silvicultura brasileira, propondo o diálogo entre comunidades e empresas florestais sob a mediação do poder público.

Existem várias definições e discussões sobre a responsabilidade social empresarial (RSE) (BESSA, 2006; ASHLEY, 2005; MELO NETO e FROES, 2001; DUARTE e DIAS, 1986; OLIVEIRA, 2007) e certa divergência em relação aos elementos que estariam inseridos nesse conceito, os quais variam conforme os entendimentos sobre a função da empresa. Apesar de a questão ser entendida de forma diversa entre diferentes grupos sociais, o conceito de responsabilidade social vem evoluindo e se consolidando como categoria de análise importante para se discutir a sustentabilidade. Segundo Melo Neto e Froes (2001), os principais vetores da RSE são: apoio ao desenvolvimento da comunidade onde atua; preservação do meio ambiente; investimento no bem-estar dos funcionários, seus dependentes e em um ambiente de trabalho agradável; comunicações transparentes; retorno aos acionistas; e sinergia com os parceiros e satisfação dos clientes e, ou, consumidores.

R. Árvore, Viçosa-MG, v.34, n.2, p.355-365, 2010
Para as empresas é importante conhecer, avaliar e adequar suas ações no campo social para que o reconhecimento das práticas responsáveis seja legitimado pela sociedade. Se a responsabilidade social empresarial pode também ser medida pelo nível de atuação da empresa na comunidade e através da sinergia com os seus parceiros (MELO NETO e FROES, 2001), pode-se dizer que a atuação social de uma empresa ou setor pode ser mensurada a partir da identificação de atores, construção e análise de sua rede social.

Entre as diversas significações que a "rede" (network) vem adquirindo, Marteleto (2001) citou o sistema de nodos e elos, uma estrutura sem fronteiras ou uma comunidade não geográfica. Segundo Marteleto, a rede social deriva desse conceito e "passa a representar um conjunto de participantes autônomos, unindo ideias e recursos em torno de valores e interesses compartilhados”.

A análise de redes sociais (ARS) é uma ferramenta que pode ser utilizada tanto no campo da pesquisa teórica quanto na definições práticas de atuação pelas organizações. Para as análises teóricas, mostra-se vasto o campo de estudo das várias formas de relação entre organizações plurais, especialmente ao se considerarem os contextos do debate socioambiental. Para Kauchakje et al. (2006), a força do instrumento conceitual e metodológico da rede está em perceber e possibilitar a análise de fenômenos heterogêneos, ou seja, que não podem ser analisados como pertencentes a um único sistema.

Alguns conceitos fundamentais para a análise de redes sociais são: ator - indivíduo ou organização analisada, também denominada “nó”; laço — ligação estabelecida entre os nós; díade — relação estabelecida entre um par de atores; subgrupo - conjunto de atores e suas relações ou um conjunto de nós e laços; rede social - conjunto finito de atores e as relações entre eles (ROSSONI et al., 2008).

Assim, considerando o debate socioambiental emergente nas ciências florestais (GOMES et al., 2006; OLIVEIRA, 2007), este trabalho teve como objetivo propor a utilização da análise de redes sociais (ARS) como metodologia para o estudo de arranjos institucionais no setor, como possibilidade para a pesquisa empírica da responsabilidade social empresarial. 


\section{METODOLOGIA}

A base de dados para o estudo foi o Relatório de Responsabilidade Socioambiental do ano 2006 da Bracelpa (Associação Brasileira de Celulose e Papel), que apresenta os projetos realizados pelas empresas do setor de celulose e papel e suas parceiras. O trabalho considera a estrutura teórica proposta por Nardelli e Griffith (2003b), apreendendo a empresa florestal como um sistema aberto.

O Relatório apresenta dados sobre a atuação social da indústria e os projetos que envolvem comunidades, funcionários e familiares para o desenvolvimento econômico; saúde; educação, treinamento e capacitação profissional; meio ambiente; cultura; apoio à comunidade; esporte, integração e lazer; e voluntariado (BRACELPA, 2006). Porém, para o desenvolvimento deste estudo, apenas o capítulo de projetos ambientais foi considerado. Esse Relatório tem importância para o setor e é rico em informações para pesquisa socioambiental, no entanto não capta todas as informações sobre as ações e articulações dos atores, nem outras redes das quais eles façam parte.

As organizações participantes dos projetos ambientais identificadas a partir do Relatório citado foram classificadas em: primeiro setor (Estado), segundo setor (setor produtivo e suas representações) e o terceiro setor (organizações não governamentais sem fins lucrativos e de interesse público). As informações necessárias para essa classificação foram obtidas a partir de dados das páginas eletrônicas das organizações pertencentes à rede e orientadas pela Tabela 1, elaborada com o intuito de classificar os atores sociais.

As organizações foram numeradas e classificadas de acordo com o setor que representavam, recebendo o atributo: “1” - para o setor público ou primeiro setor,
"2" para o setor privado com fins lucrativos ou segundo setor e " 3 ” para as organizações sem fins lucrativos ou terceiro setor. Na classificação adotada neste trabalho, o termo Organização da Sociedade Civil de Interesse Público (OSCIP) não foi utilizado, uma vez que nem todos os atores do terceiro setor possuem essa qualificação, e essa informação não estava disponível para todas as organizações nos meios consultados (relatório e internet). Utilizou-se, então, o termo "terceiro setor”, ainda que esse termo não se constitua em termo jurídico. As organizações não governamentais foram classificadas como segundo ou terceiro setor, a depender de seu vínculo mais forte com o interesse público ou com o interesse privado, em se tratando do desenvolvimento de suas atividades-fins. Dessa forma, organizações não governamentais com atividades-fins vinculadas à iniciativa privada foram consideradas como pertencentes ao segundo setor. As organizações não governamentais sem fins lucrativos e com prioridade no desenvolvimento de ações de interesse público e criadas a partir do esforço da iniciativa privada foram consideradas como pertencentes ao terceiro setor ${ }^{1}$.

Como o Relatório analisado é um documento que foi elaborado com fins institucionais e, dessa forma, não apresentava as informações padronizadas sobre as parcerias em termos quantitativos e qualitativos, foi necessário o estabelecimento de alguns critérios de análise para possibilitar a elaboração da matriz relacional necessária ao processamento de dados pelo programa de análise - UCINET.

Primeiramente, definiu-se como propriedade relacional de análise a existência de parceria entre organizações. Assim, a significação da relação entre atores ou nós foi considerada como a existência de vínculo através da realização de projetos ambientais, independentemente do sentido da ligação, ou seja,

Tabela 1 -Classificação das organizações no primeiro, segundo e terceiro setor.

Table 1 - Classification of the organizations in the public, private and outsourced sectors.

\begin{tabular}{|c|c|c|c|}
\hline & Primeiro Setor & Segundo Setor & Terceiro Setor \\
\hline Direito & Público & Privado & Privado \\
\hline Interesse & Público & Privado & Público \\
\hline Fins lucrativos & Não & Sim / Não & Não \\
\hline Atividade econômica & Não & Sim / Não & Sim / Não \\
\hline Entidades(exemplos) & $\begin{array}{c}\text { Órgãos autárquicos de } \\
\text { qualquer esfera do poder } \\
\text { público }^{1} \text {; associações públicas } \\
\text { (cooperativas }{ }^{2} \text {. }\end{array}$ & $\begin{array}{l}\text { Sociedades empresárias; } \\
\text { Associações de interesse privado; } \\
\text { Sociedades simples. }\end{array}$ & $\begin{array}{l}\text { OSCIP’s; Associações; } \\
\text { Fundações; Organizações } \\
\text { religiosas }^{3} \text {.(Footnotes). }\end{array}$ \\
\hline
\end{tabular}


de qual instituição foi responsável por estabelecer o contato. Dessa forma, os vínculos foram considerados não orientados. Em relação à valoração, as relações poderiam representar o tempo de parceria ou o montante de recursos envolvidos, tornado os vínculos ponderados. Porém, essas informações não se encontravam disponíveis e padronizadas para todos os projetos, e, portanto, os vínculos foram considerados binários - representando a presença ou a ausência da propriedade relacional (parceria), sem atribuir uma escala de valores a essa propriedade. Atribuiu-se o valor “ 1 ” para a existência de parceria entre as organizações e o valor " 0 ” para a ausência.

Foram considerados apenas os parceiros diretos nas ações. Duas ou mais instituições apresentaram mais de uma ação conjunta sendo realizada. Nesses casos foi considerada apenas a parceria entre elas, e não o número de projetos ${ }^{2}$ que desenvolviam.

Esses dados foram inseridos em uma planilha, resultando em uma matriz relacional simétrica que representa a existência ou ausência de parceria entre cada uma das organizações (representadas pelos números de 1 a 80 ) com as demais. Os dados foram processados primeiramente considerando as relações das empresas associadas da Bracelpa entre si (Figura 1) e, posteriormente desconsiderando-se essas relações
(Figura 2). A relação entre as empresas associadas da Bracelpa permite conectar os subgrupos, delimitando a rede de projetos ambientais da Associação do setor de celulose e papel (Figura 3).

As informações relacionadas ao setor de pertencimento foram inseridas no programa a partir de uma planilha específica para os atributos dos nós, o que possibilita a classificação dos atores e a visualização desse atributo nos sociogramas.

O Relatório contém ainda diversas outras atividades desenvolvidas pelas empresas e que atingem grande número de pessoas e comunidades. Porém, essa análise teve como foco a relação entre instituições, considerando-se apenas os casos em que mais de uma organização estivesse envolvida. Duas ou mais instituições apresentaram mais de uma ação conjunta sendo realizada. Nesses casos foi considerada apenas a parceria entre elas e não o número de projetos que desenvolviam.

Os dados foram processados através do software UCINET(BORGATTI et al., 2002; QUIROGA, 2003) para a obtenção de um sociograma (BORGATTI, 2002), utilizando-se o critério de existência ou não de parceria entre organizações e de informações quantitativas que retratam melhor a realidade estudada. As informações quantitativas obtidas foram as medidas de centralidade.

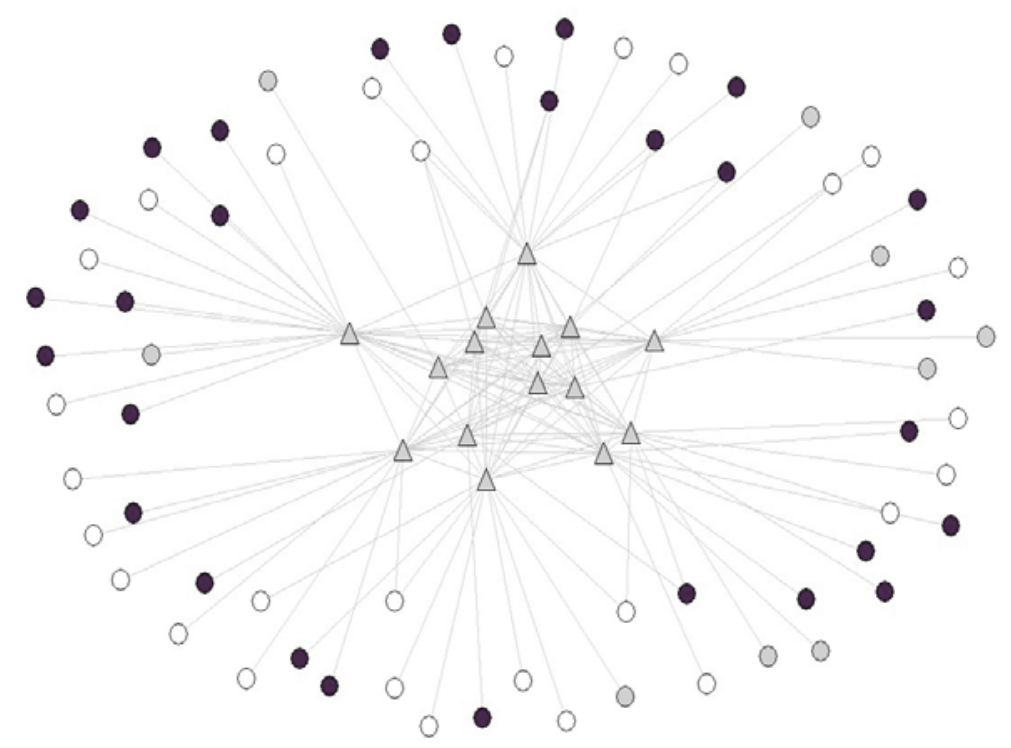

$\triangle$ Empresas de papel e celulose associadas da Bracelpa. Companies of the Brazilian Pulp and Paper Association

○ Organizações do primeiro setor. Public Sector organizations

- Outras organizações do segundo setor. Other private organizations

- Organizações do terceiro setor.

Outsourced organizations

Figura 1 - Articulação entre diferentes setores na rede de responsabilidade socioambiental da indústria de celulose e papel. Figure 1 - Articulation among sectors on the social-environmental responsibility network of the pulp and paper sector.

R. Árvore, Viçosa-MG, v.34, n.2, p.355-365, 2010 

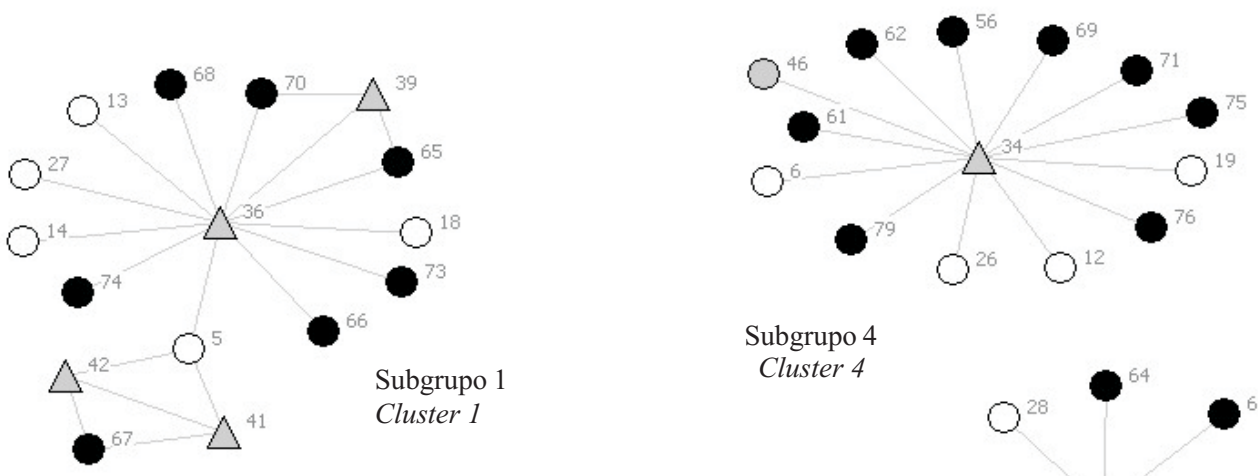

Subgrupo 4

Cluster 4
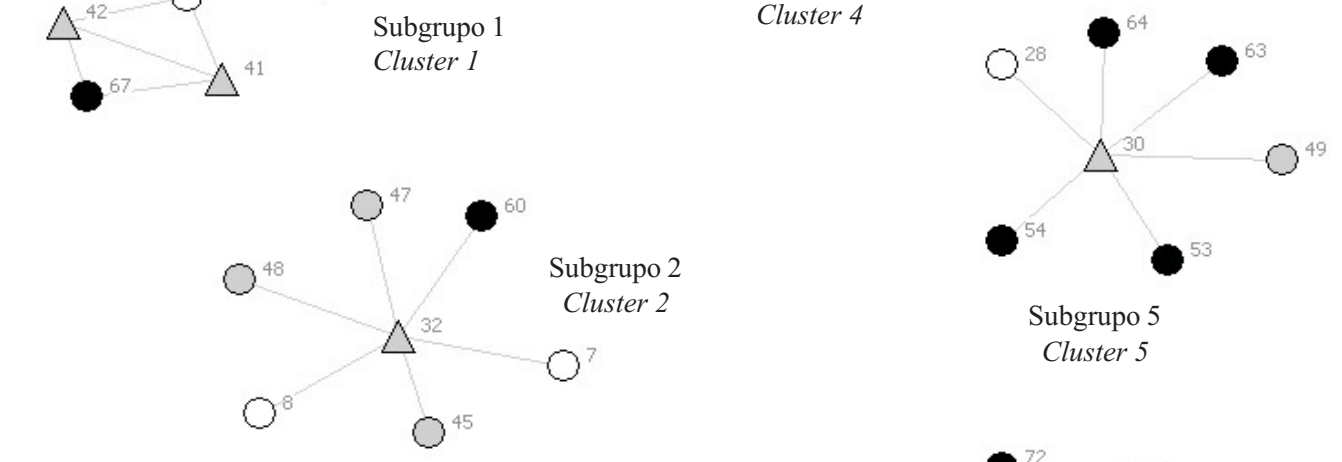

Cluster 5

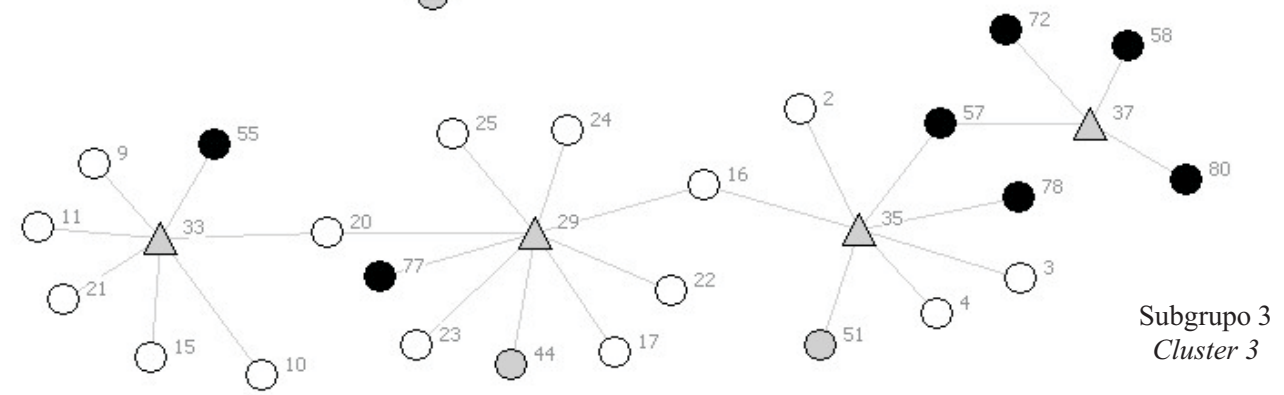

Figura 2 - Identificação dos subgrupos da rede de responsabilidade ambiental no setor de celulose e papel. Figure 2-Cluster identification on the pulp and paper environmental network.

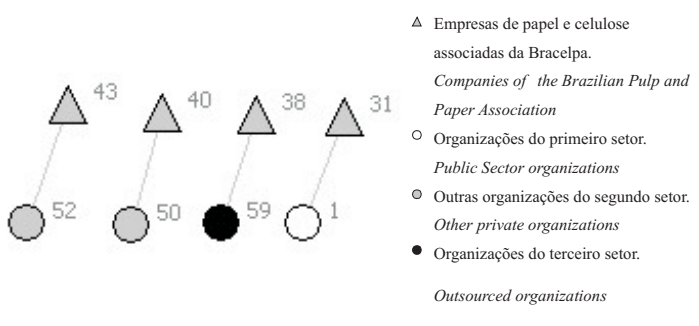

Figura 3 - Díades presentes na rede socioambiental no setor de celulose e papel.

Figure 3 - Dyads on the pulp and paper social environmental network.
Foram calculadas as medidas grau de centralidade, grau de proximidade e grau de intermediação ${ }^{3}$.

O grau de centralidade refere-se ao número de laços diretos de um ator ou nó e informa com quantos outros nós se encontravam conectados (QUIROGA, 2007). Essa informação reflete a centralidade do ator em relação aos demais e pode ser relacionada à sua importância na rede. Para Marteleto (2001), um indivíduo é central em relação à informação quando, por seu posicionamento, ele recebe informações vindas da maior parte do ambiente da rede, o que o torna fonte estratégica. Alto grau de centralidade torna o ator referência dentro da rede, pelo fato de ser um potencial na disseminação de informações.

R. Árvore, Viçosa-MG, v.34, n.2, p.355-365, 2010 
Tabela 2 - Organizações com os 10 maiores graus de centralidade, em ordem decrescente, da rede socioambiental do setor de celulose e papel

Table 2 - Organization with the 10 greatest degrees of centrality, in decreasing order, of the socio-environmental network of the cellulose and paper sector.

\begin{tabular}{ccc}
\hline Organização & Setor & $\begin{array}{c}\text { Grau de } \\
\text { centralidade } \\
\text { (degree) }\end{array}$ \\
\hline 34 & 2 & 27 \\
36 & 2 & 25 \\
29 & 2 & 23 \\
33 & 2 & 21 \\
35 & 2 & 21 \\
30 & 2 & 20 \\
32 & 2 & 20 \\
37 & 2 & 18 \\
39 & 2 & 16 \\
41 & 2 & 16 \\
42 & 2 & 16 \\
31 & 2 & 15 \\
38 & 2 & 15 \\
40 & 2 & 15 \\
43 & 2 & 15 \\
5 & 1 & 3 \\
57 & 3 & 2 \\
65 & 3 & 2 \\
67 & 3 & 2 \\
16 & 1 & 2 \\
70 & 3 & 2 \\
20 & 1 & 2 \\
\hline
\end{tabular}

O grau de intermediação indica a frequência com que aparece um nó no trecho mais curto (ou geodésico) que conecta outros dois (QUIROGA, 2007). A centralidade de intermediação (Betweeness centrality) indica o potencial daqueles que servem de intermediários (MARTELETO, 2001). Segundo Marteleto, o valor calculado para a intermediação representa quanto um ator atua como ponte, facilitando o fluxo de informações na rede. Pode-se dizer que essa medida retrata quanto o ator exerce o papel de facilitar para os demais no alcance dos atores da rede.

Para se avaliar o grau de proximidade, é necessário conhecer o significado de distância na análise de redes sociais, a qual indica o caminho que conecta dois atores. Distância nesse caso é a sequência de nós e laços que levam de um ator a outro. Segundo Quiroga (2007), a proximidade representa a capacidade que um ator possui de alcançar os demais. Dessa forma, essa medida representa quanto um ator alcança os nós da rede, o que mede a sua independência de atuação na rede em relação à atuação de outros atores.
O enfoque das análises envolvendo as medidas de centralidade considerou alguns critérios, em função dos resultados obtidos e do número de organizações envolvidas. Assim, para o grau de centralidade foram recortadas as organizações que apresentaram os 10 maiores valores, totalizando 22 organizações (Tabela 2). No caso da intermediação, foram elencadas as organizações que apresentaram qualquer valor diferente de zero, totalizando 15 organizações (Tabela 4). E, para o grau de proximidade, foram recortadas as organizações que apresentaram os cinco maiores valores, em um total de 31 organizações (Tabela 3).

Tabela 3 - Organizações com os cinco maiores graus de proximidade, em ordem decrescente, da rede socioambiental do setor de celulose e papel

Table 3 - Organizations with the five greatest proximity degrees, in decreasing order, of the socioenvironmental network of the cellulose and paper sector.

\begin{tabular}{|c|c|c|}
\hline Organização & Setor & $\begin{array}{c}\text { Grau de proximidade } \\
\text { (closenness) }\end{array}$ \\
\hline 1 & 1 & 301.000 \\
\hline 59 & 3 & 301.000 \\
\hline 50 & 2 & 301.000 \\
\hline 52 & 2 & 301.000 \\
\hline 67 & 3 & 299.000 \\
\hline 58 & 3 & 298.000 \\
\hline 72 & 3 & 298.000 \\
\hline 80 & 3 & 298.000 \\
\hline 53 & 3 & 296.000 \\
\hline 54 & 3 & 296.000 \\
\hline 45 & 2 & 296.000 \\
\hline 7 & 1 & 296.000 \\
\hline 8 & 1 & 296.000 \\
\hline 60 & 3 & 296.000 \\
\hline 47 & 2 & 296.000 \\
\hline 48 & 2 & 296.000 \\
\hline 49 & 2 & 296.000 \\
\hline 63 & 3 & 296.000 \\
\hline 64 & 3 & 296.000 \\
\hline 28 & 1 & 296.000 \\
\hline 55 & 3 & 295.000 \\
\hline 2 & 1 & 295.000 \\
\hline 3 & 1 & 295.000 \\
\hline 4 & 1 & 295.000 \\
\hline 9 & 1 & 295.000 \\
\hline 10 & 1 & 295.000 \\
\hline 11 & 1 & 295.000 \\
\hline 15 & 1 & 295.000 \\
\hline 21 & 1 & 295.000 \\
\hline 51 & 2 & 295.000 \\
\hline
\end{tabular}


Tabela 4 - Organizações que apresentaram graus de intermediação diferentes de zero, em ordem decrescente, da rede socioambiental do setor de celulose e papel.

Table 4 - Organizations that present intermediation grades different from zero, in decreasing order, of the socio-environmental network of the cellulose and paper sector.

\begin{tabular}{ccc}
\hline Organização & Setor & $\begin{array}{c}\text { Grau de Intermediação } \\
\text { (betweenness) }\end{array}$ \\
\hline 34 & 2 & 936.000 \\
36 & 2 & 687.167 \\
29 & 2 & 589.000 \\
33 & 2 & 484.500 \\
30 & 2 & 453.000 \\
32 & 2 & 453.000 \\
35 & 2 & 446.500 \\
37 & 2 & 265.000 \\
31 & 2 & 78.000 \\
38 & 2 & 78.000 \\
40 & 2 & 78.000 \\
43 & 2 & 78.000 \\
39 & 2 & 67.500 \\
41 & 2 & 60.167 \\
42 & 2 & 60.167 \\
\hline
\end{tabular}

\section{RESULTADOS}

Foram identificadas 65 diferentes organizações participando de projetos ambientais com as empresas de base florestal. Entre todos os atores sociais envolvidos nas parcerias, 24 eram organizações privadas, sendo 15 empresas do setor de celulose e papel; 28 organizações governamentais; e 28 organizações do terceiro setor, totalizando 80 organizações.

O processamento das informações extraídas do relatório resultou em dois sociogramas, possibilitando a visualização de uma rede de organizações formada por empresas de base florestal, organizações não governamentais, órgãos públicos e empresas privadas, a partir do desenvolvimento de projetos ambientais. As empresas de base florestal formaram o núcleo dessa rede, uma vez que os dados foram considerados a partir das iniciativas desse setor, representado pelas empresas associadas à Bracelpa (Figura 1).

O desenho da rede permite a identificação de cinco subgrupos, ancorados por oito empresas do setor florestal. Apesar de o subgrupo 3 englobar sozinho quatro dessas empresas (Figura 2), estas não são individualmente as que recebem o maior número de informações da rede. As oito empresas do setor florestal presentes nos subgrupos apresentam os maiores valores para a centralidade e para a intermediação, entre todas as organizações avaliadas na rede (Tabelas 2 e 4). As quatro empresas com os maiores graus de centralidade também são as quatro com os maiores graus de intermediação, e duas delas encontravam-se no subgrupo 3 e duas, com os maiores valores dessas medidas, nos subgrupos 1 e 2 .

A Tabela 2 mostra as organizações que apresentaram até o mínimo de dois vínculos. As demais organizações, que não aparecem nessa tabela e somam um total de 58 organizações, apresentaram apenas um vínculo, apresentando pouca importância em relação à centralização de informações.

No caso da intermediação, 65 atores apresentaram valores iguais a zero para essa medida de centralidade. As 15 organizações que apresentaram algum grau de intermediação para essa rede eram as empresas associadas à Bracelpa.

Os graus de proximidade obtidos mostram, entre as organizações da rede com os cinco maiores valores dessa medida, a existência de 12 atores do governo - prefeituras, universidades, instituições de pesquisa pública, diretorias de ensino; 12 organizações não governamentais - associações e fundações de preservação do meio ambiente; e sete empresas privadas, que não pertencem ao setor florestal, mas realizam ações ambientais em parceria com elas - consultorias, imprensa e universidades privadas.

Excluindo a conexão entre as empresas da Associação, identificam-se os subgrupos de cada uma das empresas com outros setores da sociedade (Figura 2). O sociograma permitiu, ainda, identificar as díades, ou seja, os pares de atores vinculados entre si e descolados dos subgrupos (Figura 3), apresentando fracos laços relacionais com a rede.

\section{DISCUSSÃO}

É importante ressaltar que a base de dados utilizada não se refere a uma rede formal, assim estabelecida e designada pela Associação ou pelo setor. Porém, as informações agrupadas no relatório foram utilizadas com o intuito de demonstrar algumas possibilidades para estudar as relações entre atores, buscando elementos estratégicos para fortalecer a atuação socioambiental do setor.

R. Árvore, Viçosa-MG, v.34, n.2, p.355-365, 2010 
Instrumentalmente, a análise a partir da identificação e da classificação dos atores sociais permite observar, na articulação das empresas de celulose e papel, aquelas que mais e menos se relacionam com outras organizações da sociedade civil, com o terceiro setor ou com o estado, e as possibilidades de novas associações que interessem ao coletivo constituído. Além disso, os sociogramas possibilitam a visualização de subgrupos de relacionamento e inferências para cada uma das organizações separadamente.

A obtenção de dados quantitativos e qualitativos sobre os arranjos formados pelas empresas do setor florestal possibilita conhecer subgrupos de atuação. A constituição desses subgrupos pode ser relacionada a fatores territoriais, culturais, gerenciais, dependendo da inserção e análise de outros atributos aos nós da rede, como localização geográfica, modelos de gestão adotados pela empresa, cultura empresarial etc.

Os dados do relatório foram tratados com a metodologia de representação e análise de redes. Essa metodologia, como demonstrado em trabalhos de Marteleto (2001), Kauchakje (2006), Marques (2006) e Quiroga (2007), possibilita obter e analisar características de articulações entre pessoas e organizações. Porém, é importante frisar que são características que não representam toda a dinâmica relacional entre esses atores, mas sim aquelas passíveis de serem capturadas pela metodologia e pela fonte de dados utilizadas. Nesse caso, a Bracelpa pode ser entendida como articuladora e potencializadora dessa rede, sendo responsável pela possibilidade de intermediação no caso estudado. Porém, os atores envolvidos fazem parte de outras redes que poderiam ser identificadas através de outros documentos ou metodologia.

Quando se trata de diálogo e de parcerias entre diferentes poderes, lembra-se de Kauchakje et al. (2006), para os quais novos arranjos institucionais e de cooperação estão se estabelecendo em forma de redes nas organizações. Esses autores comentaram que nessa estrutura os pontos não se relacionam por subordinação e, sim, por afinidades - algumas sociais, outras culturais, econômicas ou funcionais. A preocupação com o meio ambiente e o desenvolvimento de projetos ambientais, no caso estudado, cria uma identidade que conecta os membros em uma rede de pertencimento com um interesse em comum.
O Estado, a partir especialmente do final do século XIX e início do XX, é um ator central na regulação dos campos social e ambiental, tendo responsabilidades interventivas diretas. Para Wanderley e Raichelis (2001), na atualidade o Estado passa a dividir as responsabilidades públicas com outras organizações. Os resultados indicam que os arranjos institucionais são heterogêneos em sua composição entre os subgrupos da rede estudada. Enquanto o subgrupo 3 interage preferencialmente com o Estado, o subgrupo 4 estabelece maior número de relações com o terceiro setor (Figura 2).

Para compreender as relações preferenciais do subgrupo 4, seria importante considerar e investigar mais detalhadamente alguns aspectos. Por exemplo, a empresa 34 articula-se com nove ONGs, sendo quatro ambientalistas representativas em caráter nacional e um internacional, todas com reconhecida gestão profissional dos projetos empreendidos; e uma delas é uma ONG empresarial, isto é, fundada pela própria empresa do setor (34). Assim, emerge a possibilidade de análise da cultura de gestão das empresas, que pode influenciar na escolha dos parceiros em função de uma preferência por articulações da empresa com ONGs de grande porte e significativo grau de profissionalização.

Essa característica da cultura de gestão empresarial também é fator relevante na compreensão do padrão de relações do subgrupo 3, isto é, com preferência para as articulações com organizações públicas de ensino e pesquisa, em maior número, e com a administração pública de abrangências regional e local. Essas relações permitem investigar as atitudes, noções e percepções do empresariado a respeito da responsabilidade social em função dos atributos dos parceiros nos projetos.

É possível pela representação da rede inferir novos arranjos de relação, no sentido de potencializar a proposta de desenvolvimento de ações de responsabilidade socioambiental pelo setor, articulando saberes, recursos e tecnologia. As ações desenvolvidas podem ser potencializadas a partir das experiências dos subgrupos observando os atores estratégicos considerando o seu grau de centralidade. Dessa forma, ligações mais eficientes da rede passam pela articulação dos subgrupos, especialmente dos subgrupos 1 e 4 com o subgrupo 3, pelo fato de as empresas 34 e 36 (subgrupos 1 e 4) apresentarem os maiores graus de centralidade e intermediação e o subgrupo 3, o maior número de atores da rede. 
O subgrupo 3 agrega 28 organizações, concentrando, dessa forma, grande público institucional, sendo sete representantes do terceiro setor, 15 do poder público e seis da iniciativa privada, dos quais quatro são de base florestal. O sociograma sugere que as empresas associadas à Bracelpa pertencentes a esse subgrupo (empresas 29, 33, 35 e 37 da Figura 3) podem funcionar como pontes para integrar diferentes organizações. Outras organizações que não fazem parte dessa rede podem ser integradas a ela através de qualquer uma dessas quatro empresas, podendo se beneficiar do acesso aos fluxos de informações, saberes e ações. Para Marteleto e Silva (2004), o acesso à informação, especialmente aquela existente fora do grupo, e sua importância para o desenvolvimento, seja das comunidades, seja das empresas, é um elemento-chave a ser investigado, utilizando-se a ARS.

Essas “organizações-chave” podem ser utilizadas como referenciais para o trabalho de diálogo entre setores, ou entre organizações heterogêneas dentro de um mesmo setor para, por exemplo, discutir temas polêmicos e relevantes do ponto de vista ambiental, contribuindo para a construção de um saber coletivo. Os atores da esfera pública que se encontram inseridos na rede podem facilitar o diálogo entre a comunidade e as empresas, mediação essa identificada por Oliveira (2007) como desafio da silvicultura para atender às suas demandas sociais.

Cabe ressaltar que o mero vínculo institucional não garante maior proximidade e integração à rede. Mas o fortalecimento do vínculo seria obtido pela participação efetiva nas ações socioambientais desenvolvidas e pela pró-atividade no desenvolvimento de ações, congregando os partícipes. Para Capra (2006 [1997]), à medida que uma parceria se processa, cada parceiro passa a entender melhor as necessidades dos demais, orientando uma parceria verdadeira e de confiança, na qual ambos os parceiros aprendem e mudam em um processo de coevolução. Pode-se dizer que o sociograma completo (Figura 1) demonstra sinergia com diferentes parceiros que, conforme citado por Melo Neto e Froes (2001), é um dos vetores da responsabilidade social empresarial (RSE).

Nardelli e Griffith (2003a) verificaram que os maiores conflitos na construção de uma visão de sustentabilidade para o setor florestal se encontram entre os grupos econômicos e sociais. Esses autores indicaram que a câmara ambiental aparece como mediadora do processo, por apresentar elementos de consenso com ambas. Dessa forma, por reunir principalmente organizações da câmara ambiental, os atores da rede identificada nesse trabalho podem se inserir nos fóruns de mediação que discutem as problemáticas socioambientais em torno do setor florestal. Segundo Sachs (2004), o planejamento moderno é essencialmente participativo e dialógico.

Nardelli e Griffith (2003b) consideraram que a legitimidade de uma empresa ou empreendimento florestal é conferida pela sua conformidade às expectativas do campo organizacional. Para esses autores, o setor florestal apresenta dinâmica institucional própria, que vem alterando a maneira pela qual as empresas respondem às questões ambientais, destacando que a dinâmica organizacional é movida pela busca da legitimidade, e não, explicitamente, por maior eficiência técnica. Conhecer esse campo organizacional e suas inter-relações pode facilitar o entendimento da dinâmica institucional.

Segundo Gomes et al. (2006) ${ }^{4}$, as empresas podem, entre outras coisas, desenvolver novas atividades, iniciar novos projetos e ampliar os stakeholders a serem atendidos por meio de parcerias e alianças estratégicas. Assim, o conhecimento da dinâmica da rede e o seu monitoramento ao longo do tempo a partir da ARS podem indicar se essa potencialização está ocorrendo ou não e qual a percepção das comunidades envolvidas a respeito da efetividade dos projetos desenvolvidos.

O alcance dos resultados dos projetos ambientais da rede pode ser analisado em futuros trabalhos através da inserção de novos atributos relacionais à matriz. Da mesma forma, análises qualitativas podem enriquecer a análise das parcerias e da RSE, incluindo o grau de participação e de satisfação das partes no processo, além da orientação dos laços, conteúdo e natureza das ações empreendidas. A rede aqui estudada representa as interações que se formam na dimensão ambiental, porém outras dimensões da responsabilidade social empresarial poderiam ser avaliadas, como os projetos de saúde, de cultura e de desenvolvimento econômico, gerando outros atributos para análise.

\section{CONCLUSÕES}

Este artigo demonstra possibilidades de utilização da metodologia de análise de redes sociais (ARS) no âmbito do setor florestal, no que tange à responsabilidade socioambiental. A construção gráfica de uma rede com

R. Árvore, Viçosa-MG, v.34, n.2, p.355-365, 2010 
dados das parcerias na realização de projetos permite apontar as articulações do setor com outros atores, inseridos em diferentes contextos culturais, sociais e econômicos.

A análise permite perceber o fluxo de informações e a construção social do grupo a partir de dados quantitativos e qualitativos, fornecendo informações estratégicas para a constituição de uma rede formal. O estudo indica que a Bracelpa pode ser articuladora e potencializadora dessa rede socioambiental através do fortalecimento dos laços relacionais entre os subgrupos. A associação apresenta importante função na comunicação entre os atores e concentra a capacidade de mobilização de organizações para a realização de novos projetos.

Outros atributos dos atores, além do setor de pertencimento, como localização, áreas temáticas, conteúdo dos projetos, resultados das ações, percepção da atuação pelos atores etc. podem ser explorados no intuito de aprofundar a análise da rede em questão.

Este trabalho traz o conceito de redes sociais e de análise de redes para as Ciências Florestais. Acredita-se que os inúmeros recursos da análise de redes podem ser úteis para futuros estudos relacionados ao setor. Em especial, os resultados apontaram caminhos para novas pesquisas sobre cultura gerencial, multiplicação de informações, dinamização das ações, sinergia com parceiros e sobre o potencial de incorporação da metodologia pelas próprias organizações do setor.

\section{AGRADECIMENTOS}

À Associação Brasileira de Celulose e Papel Bracelpa, por permitir a utilização dos dados do Relatório Socioambiental nesta pesquisa.

\section{REFERÊNCIAS}

ASHLEY, P. A. Ética e responsabilidade nos negócios. 2.ed. São Paulo: Saraiva, 2005.

BESSA, F. L. B. N. Responsabilidade social das empresas: práticas sociais e regulação jurídica. Rio de Janeiro: Lúmen Júris, 2006. 293p.

BORGATTI, S. P. Netdraw visualization. Harvard: Analytic Technologies, 2002.

R. Árvore, Viçosa-MG, v.34, n.2, p.355-365, 2010
BORGATTI, S. P.; EVERETT, M. G.; FREEMAN, L. C. Ucinet for Windows: Software for Social Network Analysis. Harvard: Analytic Technologies, 2002.

\section{ASSOCIAÇÃO BRASILEIRA DAS EMPRESAS DE CELULOSE E PAPEL - BRACELPA. \\ Responsabilidade socioambiental das empresas do setor de celulose e papel. São Paulo: 2006. 244p.}

CAPRA, F. A teia da vida: uma nova compreensão científica dos sistemas vivos. São Paulo: Cultrix, 2006. 256p.

\section{CASTELS, M. A era da informação:}

economia, sociedade e cultura. A Sociedade em Rede. São Paulo: Paz e Terra, 1999. v.1.

DUARTE, G. D.; DIAS, J. M. M.

Responsabilidade Social: a empresa hoje. Rio de Janeiro: LTC - Livros Técnicos e Científicos/Fundação Assistencial Brahma, 1986.

GOMES, A. N. Sustentabilidade de empresas de base florestal: o papel dos projetos sociais na inclusão das comunidades locais. 2005. Tese (Doutorado) - Universidade Federal de Viçosa, Viçosa, MG, 2005.

GOMES, A. N.; SOUZA, A. L.; COELHO, F. M. G. Sustentabilidade de empresas de base florestal: o papel dos projetos sociais na inclusão das comunidades locais. Revista Árvore, v.30, n.6, p.951-960, 2006.

KAUCHAKJE, S. et al. Redes sócio-técnicas u participación ciudadana: propuestas conceptuales y analíticas para el uso de las TICs. REDES Revista Hispana para el Análisis de Redes Sociales, v.11, n.3,2006.

MARQUES, E. C. Redes sociais e poder no Estado brasileiro: aprendizados a partir de políticas urbanas. Revista Brasileira de Ciências Sociais, v.21, n.60, p.15-41, 2006.

MARTELETO, R. M. Análise de redes sociais: aplicação nos estudos de transferência da informação. Ciência da Informação, v.30, n.1, p.71-81, 2001. 
MARTELETO, R. M.; SILVA, A. B. O. Redes e capital social: o enfoque da informação para o desenvolvimento local. Ciência da Informação, v.33, n.3, p.41-49, 2004.

MELO NETO, F. P. \& FRÓES, C.

Responsabilidade social \& cidadania empresarial - a administração do terceiro setor. 2.ed. Rio de Janeiro: Qualitymark, 2001. 208p.

NARDELLI, A. M. B.; GRIFFITH, J. J. Mapeamento conceitual da visão de Sustentabilidade de diferentes atores do setor florestal brasileiro. Revista Árvore, v.27, n., p.241-256, $2003 a$.

NARDELLI, A. M. B.; GRIFFITH, J. J. Modelo teórico para compreensão do ambientalismo empresarial do setor florestal brasileiro. Revista Árvore, v.27, n.6, p.855-869, 2003b.

OLIVEIRA, P. R. S. Diagnóstico e indicadores de sustentabilidade em fomento florestal no estado do Espírito Santo. 2003. 127f. Dissertação (Mestrado em Ciência Florestal) - Universidade Federal de Vinosa, Viçosa, MG, 2003.

OLIVEIRA, P. R. S. Relação entre empresas florestais e comunidades do entorno: proposta para superação de conflitos. 2007. 110f. Tese (Doutorado) - Universidade Federal de Viçosa, Viçosa, MG, 2007.
QUIROGA, A. Introducción al análisis de dados reticulares: prácticas con UCINET6 y NetDraw 1 Versión 1. Departamento de Ciencias Políticas da Universidad Pompeu Fabra. 2003. 41p. <Disponível em http://revista-redes.rediris.es/ webredes/talleres/redes.htm>. Acesso em 24 jul. 2007.

ROSSONI, L.; SILVA, A. J. H.; FERREIRA JUNIOR, I. Aspectos estruturais da cooperação entre pesquisadores no campo de administração pública e gestão social: análise das redes entre instituições no Brasil.

Revista de Administração Pública [online]. v.42, n.6, 2008.

SACHS, I. Desenvolvimento: includente, sustentável, sustentado. Rio de Janeiro: Garamond, 2004. 152p.

SIMÕES, C. Direito para o serviço social. São Paulo: Cortez, 2007.

WANDERLEY, L. E. W.; RAICHELIS, R. Gestão pública democrática no contexto do Mercosul. In: SIERRA, G. Los rostros del Mercosur y el difícil camino de lo comercial a lo societal. Buenos Aires: Clacso, 2001. 
